\title{
Study on Physico-Chemical Parameters and Structural Characterization of Soils in Pudukkottai District of Tamilnadu, India.
}

\section{Estudio sobre parámetros fisicoquímicos y caracterización estructural de suelos en el distrito Pudukkottai de Tamil Nadu, India.}

A. Dhanalakshmi ${ }^{1}$, K. Karthikayeni Vijayakumari ${ }^{2}$, U. Surendran ${ }^{3}$,

\begin{abstract}
${ }^{1}$ Assistant Professor, Govt. Arts College for Women, Pudukkottai, Tamil Nadu, India., email: physicsdhans@gmail.com

${ }^{2}$ Assistant Professor, Govt. Arts College for Women, Pudukkottai, Tamil Nadu, India. email: kskvkumari@gmail.com
\end{abstract}

${ }^{3}$ Senior Scientist Centre for Water Resources Development and Management (CWRDM),Kerala, India email: u.surendran@gmail.com

ABSTRACT

The soil is the most important constituent to fulfilment of all the basic needs of human beings and also is an important component of our farming. The study was conducted with the main objective to investigate the soil samples of Pudukkottai district of Tamil Nadu for its physico-chemical analysis and structural characterization. The collected soil samples were analyzed for its pH, EC, Nitrogen, Phosphorus, Potassium, Zinc and Iron. Besides, the sample was characterized by FTIR studies for structural conformation. From the study the results revealed that the collected soil was red soil and its texture was sandy clay loam. The soil pH was 9.29 which was alkaline and the EC was $0.02 \mathrm{dSm}^{-1}$. The available macro-nutrients as nitrogen, phosphorus and potassium for paddy field soil samples had 118, 11 and $160 \mathrm{~kg} / \mathrm{ha}$ respectively. Micronutrients Nutrients also analyzed. FT-IR spectrum of soil was recorded spectrum of soil was shown the $\mathrm{C}-\mathrm{H}$ deformation vibrations occur at 1402 . The $\mathrm{C}=\mathrm{C}$ Stretching vibrations occur at 1644 and the $\mathrm{N}-\mathrm{H}$ Stretching vibrations occur at 2344. Management options to improve the soil fertility were discussed.

Keywords: pH, EC, Nitrogen, Phosphorus, Potassium, Zinc, FTIR, Soil fertility. 


\section{RESUMEN}

El suelo es el componentemásimportante para satisfacertodas las necesidadesbásicas de los sereshumanos y también es un componenteimportante de nuestraagricultura. El estudio se realizó con el objetivo principal de investigar las muestras de suelo del distrito Pudukkottai de Tamil Nadu para suanálisisfisicoquímico y caracterizaciónestructural. Las muestras de suelorecolectadas se analizaron para determinarsu $\mathrm{pH}, \mathrm{CE}$, nitrógeno, fósforo, potasio, zinc y hierro. Además, la muestra se caracterizó por estudios FTIR para conformaciónestructural. A partir del estudio, los resultadosrevelaron que el suelorecogido era rojo y sutextura era francoarcillosoarenoso. El pH del suelo era 9,29, que era alcalino y la CE era 0,02 dSm-1. Los macronutrientesdisponiblescomonitrógeno, fósforo y potasio para muestras de suelo de arrozalestenían 118, 11 y $160 \mathrm{~kg} \mathrm{/} \mathrm{ha,} \mathrm{respectivamente.}$ MicronutrientesNutrientestambiénanalizados. El espectro FT-IR del suelo se registró. El espectro del suelomostró que las vibraciones de deformación C-H ocurrenen 1402. Las vibraciones de estiramiento $\mathrm{C}=\mathrm{C}$ ocurrenen 1644 y las vibraciones de estiramiento $\mathrm{N}-\mathrm{H}$ ocurrenen 2344. Se discutieron las opciones de manejo para mejorar la fertilidad del suelo.

Palabras clave: pH, CE, Nitrógeno, Fósforo, Potasio, Zinc, FTIR, Fertilidad del suelo

\section{INTRODUCTION}

The soil is an important component in the lithosphere and it is available in sandwiched between the zone of atmosphere and the zone of earth with rock cover. In other words it is a part of biosphere since it is available in the intermediate zone between hydrosphere (water bodies) and the lithosphere. Soil is a media consists of mineral (chemical / inorganic), organic materials and micro and macro organisms (living forms) in which plants grow, which is a dynamic natural body on the surface of the earth. The soil is formed due to weathering of rocks and defined as the top weathered layer of the earth's crust which possess mineral, organic constituents and other living forms. The soil is a complex organization being made up of some 6 components namely mineral (inorganic) matter, organic matter, macro and micro organisms, soil moisture, Soil solution and air. Soil is a complex system and a heterogeneous polyphase consists of numerous solid components - mineral and organic some of the solid material consists of crystalline particles while some consists of amorphous gels which coal the crystals and modify their behaviour (Deshmukh, 2012). The adhering amorphous material may be Fe oxide or complex of organic compounds which attaches solid particles and binds them together. The solid phase further interacts with fluids, water and air through soil pores. Hence the whole soil system is in the state of dynamism as it alternately -Wet and dries; 
Swells and shrinks; Disperses and flocculates; Compacts and cracks; Freezes and thaws; Precipitates the salts and redissolves. In general, the soil contains $50 \%$ proposition as mineral matter and organic matter and remaining $50 \%$ with soil water and soil air (Sonawane, 2018). These constituent portions strongly alter soil structure, texture and porosity. Besides, soil air and water fluctuations depends on the management options, irrigation / rainfall etc and that will influences the air and water movement in the soil layers, and thus the soil's ability to function and growth of plants (Alvaro et al., 2007). In general, soil properties have a great influence on the soil health and quality. Among the properties, soil texture can have an intense effect on many other properties.

In recent years there is a great apprehension about the soil resource base needs to expand further than soil productivity to include a broader concept of soil quality that include all of the ecosystem functions soils do in natural and agricultural production ecosystems. In recent past, loss of soil fertility /quality is of great concern across the globe due to various degradation processes. In addition soil acts as a sink and play a major role for climate variability by performing several functions viz., regulation of runoff and influencing the flow of water in watersheds, emissions of greenhouse gases, reduction of natural and artificial wastes, and playing a vital role in maintenance of air and water quality. These functions are impaired by soil degradation (Surendran et al., 2016).

In recent years there is always a concern on the application of modern agricultural management systems / technologies and its impact on the quality of soil, water, and air. Besdies, soil is also dynamic in nature and hence, periodical assessment of the physicochemical parameters of soil to know its quality is the need of the hour. The sample was collected from Pudukkottai district and its physic-chemical analysis have been performed to know its different parameters like pH, EC, Nitrogen, Phosphorous, Potassium Zinc an Iron. Also sample was characterized by FT-IR Studies for structural conformation. This paper suggests the possible way by which soil properties can be evaluated and understand that the weather soil quality is being negatively affected, improved, or maintained under given management systems.

\section{MATERIALS AND METHODS}

Study area: Pudukkottai district lies at North Latitude between $9^{\circ} 50^{\prime}$ and $10^{\circ} 40^{\prime}$ East Longitude between $78^{\circ} 25^{\prime}$ and $79^{\circ} 15^{\prime}$ with an area of $4663 \mathrm{sq} \mathrm{km}$. Pudukkottai district has the boundaries as follows viz., Trichy on west, Bay of bengal on west, Thanjavur on north and Sivaganga on south sides. There are 13 blocks and 3 municipalities. People of this district mainly depends on agriculture as their main occupation. Atmospheric 
temperature is between 21.3 and $41^{\circ} \mathrm{C}$ and climate is hot in this district, April to June are the hottest months and November to January are the coldest months. Generally a dry and hot climate prevails in this District. The actual annual rainfall was put at $526.8 \mathrm{~mm}$ during 2016-17 against the normal rainfall of $887.4 \mathrm{~mm}$ for the district. The annual precipitation is lesser than normal rainfall by $360.6 \mathrm{~mm}$. About $243.2 \mathrm{~mm}$ is received in $\mathrm{SW}$ monsoon (South West), $170.6 \mathrm{~mm}$, is received in NE (North East) Monsoon, $60.6 \mathrm{~mm}$ rainfall was recorded for winter and $52.4 \mathrm{~mm}$ is received in Hot Weather Period.

Soil Sample collection: A study was conducted on the physio- chemical analysis of soil samples collected from the Aranthangi block of Pudukkottai district. Soils which have been the subject of this study were sampled to a depth of $0-15 \mathrm{~cm}$ in the paddy grown field during rabi 2018. Soil samples were taken from the identified field depending on the heterogeneity observed at different locations. Samples were taken from the paddy cultivated soil layer (upper $15 \mathrm{~cm}$ ), using a soil auger and mixing the 12 samples evenly distributed over the field to one composite sample using quartering method. The soil samples were then transferred to a sterile plastic container and were tightly closed and were transported to the laboratory immediately to avoid any impulsive changes in the physio-chemical characteristics. The samples were air dried, crushed, and gravel and other particles of more than $2 \mathrm{~mm}$ were removed with a sieve. Samples were then transferred to clean and dry containers. The collected soil sample was analyzed at Soil Testing laboratory, ICAR - Krishi Vigyan Kendra, Vamban Pudukkottai. The methodology for soil texture, $\mathrm{pH}, \mathrm{EC}$ and available $\mathrm{N}, \mathrm{P}_{2} \mathrm{O}_{5}$ and $\mathrm{K}_{2} \mathrm{O}$ and micro nutrient viz., $\mathrm{Zn}, \mathrm{Cu}, \mathrm{Fe}$ and $\mathrm{Mn}$ were analyzed and methodologies were discussed below.

$\mathrm{pH}$

$\mathrm{pH}$ is the most important physico chemical property of soil is its level strongly influences all other parameters of soil. $20 \mathrm{~g}$ of soil samples in replicates were taken and mixed with distilled water in the ratio of $(1: 2.5 \mathrm{w} / \mathrm{v})$ and allowed to settle down. Then $\mathrm{pH}$ was measured using EUTECH multi parameter instrument. usually based on the level of soil pH it has been broadly classified into acidic, neutral and alkaline soil.

Electrical conductivity: Electrical conductivity (EC) is nothing but the quantity of ions present in the soil and it can be measured easily using conductometry technique. EC of a soil solution is directly proportional to the concentration of ions. The conductivity measurement gives the presence of total soluble salts presents in the soil and is expressed as dsm-1 (deci siemens per meter). Soil EC can be measured in an easy and simple way, however it is a dependable sign of soil health, nutrient availability, crop growth dependent and biological activity and can serve as a rapid indicator of plant available nutrients. Soil suspension at the ratio of $1: 2: 5$ (soil :water) was made and used for determining the EC using conductivity bridge and expressed in $\mathrm{dsm}^{-1}$ (Jackson, 1973). 
Nutrient analysis: Organic carbon (OC) (\%) content was determined by using Walkley and Black (1934), available N (Subbiah and Asija, 1956) and available P (Olsen method), K (Ammonium acetate method) content using flame photometer (Stanford and English, 1949), calcium (Jackson, 1973), magnesium, sodium and available iron (mg/kg) (Muthuvel and Udayasoorian, 1999). Atomic Absorption Spectro photometer (Perkin-Elmer Model 2280) was used for analysis of available micronutrients such as $\mathrm{Zn}, \mathrm{Cu}, \mathrm{Mn}(\mathrm{mg} / \mathrm{kg})$ (Lindsay and Norvell, 1978). For instance the procedure for OC was explained below. The basic principle for the same is that OC present in sample is oxidized by chromic acid in the existence of concentrated Sulphuric acid. $\mathrm{K}_{2} \mathrm{Cr}_{2} \mathrm{O}_{7}$ on reaction with $\mathrm{H}_{2} \mathrm{SO}_{4}$ gives nascent $\mathrm{O}_{2}$ which forms $\mathrm{CO}_{2}$ after combining with carbon. Sulphuric acid hastens the digestion process by providing heat by way of dilution. During this pocess a portion of chromic acid will be used for oxidizing as stated earlier. The remaining chromic acid is determined by back titration with $0.5 \mathrm{~N}$ FS (ferrous sulphate) or FAS (ferrous ammonium sulphate) using ferroin indicator.

$$
\begin{aligned}
& 2 \mathrm{~K}_{2} \mathrm{Cr}_{2} \mathrm{O}_{7}+8 \mathrm{H}_{2} \mathrm{SO}_{4} \rightarrow 2 \mathrm{~K}_{2} \mathrm{SO}_{4}+2 \mathrm{Cr}_{2}\left(\mathrm{SO}_{4}\right)_{3}+8 \mathrm{H}_{2} \mathrm{O}+6(\mathrm{O}) \\
& 3 \mathrm{C}+6(\mathrm{O}) \rightarrow 3 \mathrm{CO}_{2}
\end{aligned}
$$

$0.5 \mathrm{~g}$ of sample was weighed (passed through $0.2 \mathrm{~mm}$ sieve) and transferred it in to a conical flask. $10 \mathrm{~mL}$ of $1 \mathrm{~N} \mathrm{~K}_{2} \mathrm{CrO}_{7}$ was added and mixed well by swirling the flask. Then $20 \mathrm{~mL}$ of concentrated $\mathrm{H}_{2} \mathrm{SO}_{4}$ was mixed by gentle rotation for one minute to ensure complete contact of the reagent with the sample. The content was allowed to stand for 20-30 minutes. The flask was kept on an asbestos sheet to avoid burning of table due to intense heat. After 30 minutes, $200 \mathrm{~mL}$ of water, $10 \mathrm{~mL}$ of phosphoric acid and $1 \mathrm{~mL}$ ferroin indicator was added. This was titrated against the solution with $0.5 \mathrm{~N}$ ferrous ammonium sulphate. The colour developed was dull green at the beginning and then shifted to a turbid blue as the titration proceeds. The end point was very sharp. The end point was indicated by a bright green colour and OC was calculated (Walkley \& Black, 1934).

Soil spectral studies using Fourier Transform Infrared (FTIR) Spectroscopy: The IR spectroscopic measurements were made at Alagappa University, Karaikudi, Sivaganga district, Tamil Nadu with a FTIR spectrometer Model Thermo Nicolet 380, using KBr. Subsamples of soils from the study area were further dried for $72 \mathrm{~h}$. Sub portion of each sample was mixed with $\mathrm{KBr}$ and compressed under vacuum at an elevated pressure for 10 min and the spectral measurements were made. Since $\mathrm{KBr}$ does not absorb light in the IR region, 4000-500 cm- ${ }^{1}$, a complete spectrum of each soil sample could be obtained.

\section{RESULTS AND DISCUSSION}

Physico- chemical properties of soil: From the study the results revealed that the collected soil was red soil and its texture was sandy clay loam. The soil pH was 9.29 classified 
as alkaline in nature and the EC was $0.02 \mathrm{dSm}^{-1}$. The highest value of $\mathrm{pH}$ in this area is may be due to the semi arid climate caused by a calcium carbonate-rich parent material weathering (developing) in an arid or dry environment. Besides, quality of irrigation water may also cause soil alkalinity, i.e if alkalinity water is used for irrigation, however this can be managed with proper reclamation measures (Raman and Sathiyanarayanan, 2009). This high $\mathrm{pH}$ will hinder the availability of many plant nutrients in soils, including $\mathrm{Fe}, \mathrm{Zn}, \mathrm{Cu}$ and $\mathrm{Mn}$, which will be reduced at high $\mathrm{pH}$ values. Iron chlorosis in plants, caused by inadequate iron, is a common problem in alkaline soils. Phosphate, a macronutrient, may also be limited in these high $\mathrm{pH}$ soils due to its precipitation in the soil solution as insoluble calcium phosphate.

The prospective of agricultural soils was appropriately acknowledged in article 3.4 of the Kyoto Protocol and the suggestion of sequestering carbon in soils as soil organic carbon (SOC) was considered as a possible means of reducing atmospheric $\mathrm{CO}_{2}$. Furthermore, the practice of sequestering atmospheric $\mathrm{CO}_{2}$ will itself augment $\mathrm{SOC}$ pool and off-set man made / anthropogenic emissions while benefits both agricultural productivity and mitigating temperature rise. In contrary to the expectation, the results showed a very low OC content of ( $0.2 \%)$ and low available $\mathrm{N}\left(118 \mathrm{~kg} \mathrm{ha}^{-1}\right)$, respectively. The decline in soil OC and $\mathrm{N}$ contents in this field might be due to the insufficient inputs of organic substrate from the system and the area is without any crop rotation (Pathak and Rao, 1998 ; Surendran et al., 2016). The available macro-nutrients as nitrogen, phosphorus and potassium for paddy field soil samples had 118, 11 and $160 \mathrm{~kg} /$ ha respectively (Table 1 ) Based on the soil test value low nitrogen and phosphorus and medium potassium categories based on the classification of soil in Tamil Nadu. This finding could use to know the physio- chemical status of Pudukkottai district. These results of soil physicochemical showed that there is a risk to the sustainable crop production in the area. Therefore, strategies such as growing of mixed cropping system with effective soil and water conservation measures and management options for improving the soil fertility parameters needs to be adopted for increasing the soil fertility and soil quality that better addresses integrated soil management, by which crop productivity can be sustained under the changing climate scenario (Hillel, 1991 ; Surendran et al., 2016) .

Micronutrients: Plant micronutrients are required is very less, but their action depends on the mineral or organic complex which can be taken up by plant roots, soil $\mathrm{pH}$, redox potential and organic matter. The available micronutrients like zinc of the paddy field soil samples was $0.61 \mathrm{ppm}$. The Copper, iron and manganese content of paddy field soil samples was found $0.83,6.18$ and $4.45 \mathrm{ppm}$ respectively (Table 1 ). $\mathrm{Cu}$ and $\mathrm{Zn}$ are under deficit category, hence these micronutrients needs to be applied to the crops for improving the crop production. 
Table 1. Physico - chemical properties of soil samples from paddy field in Pudukkottai district

\begin{tabular}{|c|c|c|c|}
\hline Parameter & Value & Unit & Comments \\
\hline Organic Carbon & 0.2 & $(\%)$ & Low \\
\hline $\mathrm{pH}$ & 9.29 & - & Alkaline \\
\hline EC & 0.02 & $\mathrm{dSm}^{-1}$ & Non Saline \\
\hline Available N & 118 & $\mathrm{~kg} \mathrm{ha}^{-1}$ & Low \\
\hline Available P & 11.0 & $\mathrm{~kg} \mathrm{ha}^{-1}$ & Low \\
\hline Available K & 160 & $\mathrm{~kg} \mathrm{ha}^{-1}$ & Medium \\
\hline Available Zn & 0.61 & ppm & Deficient \\
\hline Available Cu & 0.83 & ppm & Deficient \\
\hline Available Fe & 6.18 & ppm & Medium \\
\hline Available Mn & 4.45 & ppm & Sufficient \\
\hline
\end{tabular}

Fourier Transform Infrared (FT-IR) Spectral of soil Studies: FT-IR spectrum of soil was recorded using Perkin Elmer FT-IR Spectrometer in the wavelength range $400-4000 \mathrm{~cm}^{-1}$ by $\mathrm{KBr}$ pellet technique. The FT-IR spectrum of soil is shown in Fig. 1. The $\mathrm{C}-\mathrm{H}$ deformation vibrations occur at 1402 . The $\mathrm{C}=\mathrm{C}$ Stretching vibrations occur at 1644 . The $\mathrm{N}-\mathrm{H}$ Stretching vibrations occur at 2344 . The vibrational frequencies and spectral assignments are shown in the Table 2. 


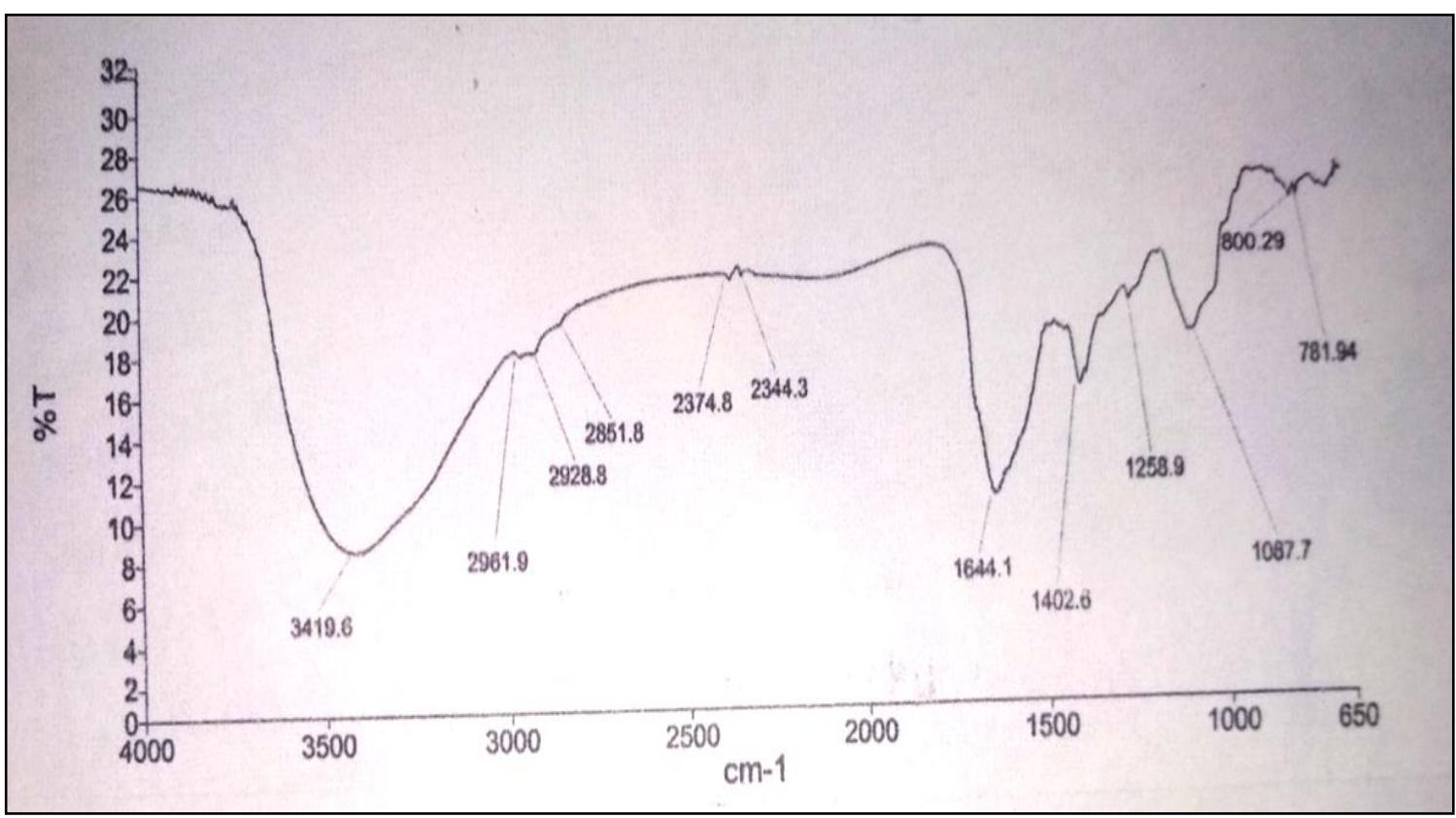

Fig. 1.FTIR Spectral assignment of soil.

Table 2. Wave number and assignment of bonds for FTIR measurements for soil sample

\begin{tabular}{|c|c|c|}
\hline S.No. & $\begin{array}{l}\text { Wave number } \\
\qquad\left(\mathrm{cm}^{-1}\right)\end{array}$ & Assignment \\
\hline 1. & $\begin{array}{c}800 \\
1402\end{array}$ & C-H deformation \\
\hline 2. & 1644 & $\begin{array}{l}\text { aromatic } \mathrm{C}=\mathrm{C} \text {; skeletal vibrations, } \\
\mathrm{C}=\mathrm{O} \text { stretching of amide groups } \\
\text { (amide } \mathrm{I} \text { band), } \mathrm{C}=\mathrm{O} \text { of quinone } \\
\text { and/or } \mathrm{H} \text {-bonded conjugated } \\
\text { ketones ; cyclic and acyclic } \\
\text { compounds of aldehydes, keones } \\
\text { and quinone }\end{array}$ \\
\hline 3. & 2344 & $\mathrm{~N}-\mathrm{H}$ Stretching \\
\hline 4. & $\begin{array}{l}2851 \\
2928 \\
2961\end{array}$ & $\begin{array}{l}\mathrm{C}-\mathrm{H} \text { Stretching ; asymmetric and } \\
\text { symmetric } \mathrm{C}-\mathrm{H} \text { stretching of } \mathrm{CH} 2 \\
\text { group }\end{array}$ \\
\hline 5. & 3419 & $\begin{array}{l}\mathrm{O}-\mathrm{H} \text { stretching, } \mathrm{N}-\mathrm{H} \text { stretching } \\
\text { (minor), hydrogen-bonded } \mathrm{OH}\end{array}$ \\
\hline
\end{tabular}

Spectral signatures from FTIR may be potentially used for characterization of different land uses if a library is developed with large number of samples without going for detailed conventional laboratory analysis (Chandrasekaran and Ravisankar, 2015). 
Over all the soil fertility is low based on the physico chemical properties and farmers needs to be trained on the solutions to improve the soil quality and it needs to be focussed on economically feasible and socially acceptable technologies. There is a wide range of management interventions (nutrient saving technologies viz., increasing the use efficiency, preventing/minimizing the losses) to influence soil quality (Surendran et al., 2016). Some of the strategies are discussed below, which are relevant to the study area a) Split applications of fertilizers can be made to match the nutrient requirement of the crop with that of the nutrient availability in soil thereby increasing the efficiency of applied fertilizers. b) Crop rotation should involve shallow rooted crop and deep-rooted crop for efficient transfer of nutrient flow from subsoil to surface soil c) Introduction of green manures and legumes in the system is one of the technological options to replenish the soil nitrogen level without any external inputs.d) Even though farmers are mainly concerned with the current season, awareness has to be created about the effects of soil fertility decline. Feedback mechanism has to be developed or included in the training programme so that everyone will know about declining soil fertility, which in turn reduce the yield in a long run e) Practice of integrated nutrient management comprising integrated usage of chemical fertilizers and other source of organic manures such as biofertilizers will result in sustainable crop yields without any detrimental effect on agro ecological balance (Hillel, 1991; Surendran et al., 2016).

As conclusion, the results from the current study concluded that the soil of Pudukkottai district, the collected soil was red soil and its texture was sandy clay loam. The soil pH was 9.29 which was alkaline and the EC was $0.02 \mathrm{dSm}^{-1}$. The available macronutrients as nitrogen, phosphorus and potassium for paddy field soil samples had 118, 11 and $160 \mathrm{~kg} / \mathrm{ha}$ respectively. FT-IR spectrum of soil was shown the $\mathrm{C}-\mathrm{H}$ deformation vibrations occur at 1402 . The $\mathrm{C}=\mathrm{C}$ Stretching vibrations occur at 1644 and the $\mathrm{N}-\mathrm{H}$ Stretching vibrations occur at 2344. This finding could use to know the physio - chemical status of Pudukkottai district. Functional groups present in the compound were confirmed by FT-IR studies. The several attributes of the soils under the cultivated lands showed overall change towards the direction of loss of their fertility. These variations of soil physicochemical properties indicate the risk to the sustainable crop production in the area. Therefore, strategies which have been discussed earlier (such as growing of mixed cropping system / crop rotation with effective soil and water conservation measures, management of soil fertility) needs to be adopted for increasing the soil fertility and soil quality that better addresses integrated soil management, by which crop productivity can be sustained under the changing climate scenario. 
Alvaro F J., Arrúe, J. L., Gracia, R. and López, M. V. 2007. Soil management effects on aggregate dynamics in semiarid Aragon (NE Spain). Science of Total Environment 378 : 179-182.

Chandrasekaran, A., and Ravisankar, R. 2015. Spatial distribution of physico-chemical properties and function of heavy metals in soils of Yelagiri hills, Tamilnadu by energy dispersive X-ray florescence spectroscopy (EDXRF) with statistical approach. Spectrochimica Acta Part A: Molecular and Biomolecular Spectroscopy, 150 : 586-601

Deshmukh, K. K. 2012. Studies on Chemical Characteristics and Classification of Soils from Sangamner Area, Ahmednagar District, Maharashtra, India, Rasayan Journal 5(1): 74-85.

Hillel, D. 1991. Research in soil physics: A review. Soil Science, 151: 30-34.

Jackson, M. L. 1973, Soil Chemical Analysis, Prentice Hall of India Private Limited, New Delhi.

Lindsay, W.L. and Norvell, W.A. (1978) Development of a DTPA Soil Test for Zinc, Iron, Manganese, and Copper. Soil Science Society of America Journal 42: 421-428.

Muthuvel, P. and C. Udayasoorian, 1999. Soil, plant, water are agrochemical analysis. Tamilnadu. Agricultural Unviersity, Coimbatore, India.

Pathak, H., and Rao, D. 1998. Carbon and nitrogen mineralization from added organic matter in saline and alkali soils. Soil biology and biochemistry, 30(6): 695-702.

Raman, N. and Sathiyanarayanan, D. 2009. Physico-Chemical Characteristics of Soil and Influence of Cation Exchange Capacity of Soil in and around Chennai, Rasayan Journal 2(4): 875-885.

Sonawane, V. 2018. Determination of Physical Parameters and Metal Ions Concentration in Soil Samples around the Parva Village, Tq. Parbhani, Dist. Parbhani. IOSR Journal of Engineering, www.iosrjen.orgISSN (e): 2250-3021, ISSN (p): 2278-8719

Stanford, S. and L. English. 1949. Use of flame photometer in rapid soil tests for $\mathrm{K}$ and $\mathrm{Ca}$. Agronomy Journal 41: 446-447.

Subbiah, B.V. and G.L. Asija. 1956. A rapid procedure for estimation of available nitrogen in soils. Current Science 25: 259-260.

Surendran, U., Ramasubramoniam, S., Raja, P., Kumar V., and Murugappan, V. 2016. Budgeting of major nutrients and the mitigation options for nutrient mining in Semi Arid Tropical Agro ecosystem of Tamil Nadu, India using NUTMON model. Environmental Monitoring and Assessment 188 (4): 1-17

Walkley, A.J. and I.A. Black. 1934. Estimation of soil organic carbon by the chromic acid titration method. Soil Science. 37: 29-38. 